\title{
Chinese Graduate Students' Experiences with Writing a Literature Review
}

\author{
Jun Qian and Eva Krugly-Smolska
}

Based on interview data, this study investigated four Chinese graduate students' experiences with writing a literature review at a medium-sized university in Canada. These students, from four subject areas, held varying perceptions of a literature review, but all saw the writing challenges that they encountered mainly as linguistic problems, especially regarding vocabulary and accuracy at the sentence level. The strategies that they used in the composing process were diverse, with each individual relying on them to varying degrees. Findings from this study suggest that Chinese graduate students need assistance in adjusting to the new academic environment and writing-genre expectations.

Reposant sur des données d'entrevues, cette étude est axée sur les expériences de quatre étudiants chinois des cycles supérieurs alors qu'ils apprenaient à rédiger une analyse documentaire dans une université de taille moyenne au Canada. Les participants, qui étudiaient dans quatre domaines différents, avaient diverses perceptions d'une analyse documentaire, mais tous interprétaient les défis rédactionnels qu'ils confrontaient comme étant surtout linguistiques, notamment lexicaux et syntaxiques. Lors de la rédaction, les étudiants ont employé une diversité de stratégies, auxquelles ils ont eu recours dans différentes mesures. Les résultats indiquent que les étudiants chinois des cycles supérieurs ont besoin d'appui dans leur adaptation à leur nouveau milieu académique et aux attentes liées à la rédaction.

\section{Introduction}

With English becoming a world language, an increasing number of English as a second language (ESL) students are seeking graduate studies in North American universities. Following this trend is a growing body of research on the acculturation of second-language (L2) students into the English-language academy. Issues emerging from the research concern the distinct nature of L2 writing, how ESL students struggle to survive in a new education system, and how their previous learning experiences influence their English writing. As evident from the literature, Chinese students have difficulties in English academic writing. However, these students' experiences with writing a literature review (LR), an important genre of academic writing, have been given little attention by researchers and educators. To explore this issue, this study investigated-through interviews-four Chinese graduate students' 
experiences with writing an LR at a medium-sized university in Canada. The purpose was to examine their perceptions of requirements for writing an LR, the challenges they encountered in writing an LR, and the strategies they used in the composing process.

\section{Insights from the Literature}

Writing a Literature Review

Writing an LR is an important part of undertaking research for a higher degree. A review of the literature can serve numerous functions. It can "provide the ... background or rationale for the study ... a demonstration of how previous research is related to the study ... and a framework for viewing the study" (Brown, 1988, p. 46). An LR also helps to avoid repetition and unnecessary work, broadens a researcher's perspective on the research, narrows down the topic, and formulates and clarifies questions that need further inquiry (Railey, 1997). There is considerable disciplinary variation in LR writing (Hyland, 1999). Even in one discipline, the criteria used to evaluate the quality of an LR differ slightly from researcher to researcher (Boote \& Beile, 2005, 2006; Maxwell, 2006). However, there is agreement that an LR is not just a summary of previous work, but a synthesis or a critical evaluation of relevant research organized around and related directly to the guiding concept of a specific thesis or research question (Gall, Borg, \& Gall, 1996).

Graduate students are also found to hold varied perceptions of an LR: list, search, survey, vehicle for learning, research facilitator, and report (Bruce, 1994). Although often viewed as boring (Swales \& Feak, 2000), it is one of the most difficult tasks encountered by graduate students in the process of writing theses or dissertations (Meloy, 2002). However, research on LR writing remains limited (Dong, 1996; Kwan, 2006; Miguel \& Nelson, 2007; Thompson, 2005). From personal observation and communication with many colleagues across the disciplines, it appears that in most programs there is no well-defined and systematic training program to prepare students for the task of writing an LR.

\section{ESL Students' Difficulties in Academic Writing}

Earlier studies indicate that ESL students from diverse cultures and educational systems often have difficulty in meeting the demands of the kind of writing required of them at the graduate level (Casanave, 2002; Casanave \& Hubbard, 1992; Paltridge, 1997). There are a number of significant differences between ESL students' writing in their first language (L1) and in English. These include "both composing processes (and subprocesses: planning, transcribing, and reviewing) and features of written texts (fluency, accuracy, quality, and structure, i.e., discoursal, morphosyntactic, and lexicosemantic)" (Silva, 1993, p. 657). 
A large percentage of ESL students tend to see their writing difficulties mainly as linguistic problems (Bitchener \& Basturkmen, 2006; Cooley \& Lewkowicz, 1997). Many of them have expressed the desire to learn "more language skills" (Leki \& Carson, 1994, p. 89). However, academic writing is a complex task that requires more than just improving linguistic abilities in the L2 (Angelova \& Riazantseva, 1999; Prior, 1998). Research indicates that many of ESL students' problems stem from inefficient writing strategies, not primarily from lack of language proficiency (Connor \& Kramer, 1995). A growing literature also reveals that students from diverse cultures and educational systems learn in varied ways and that they may differ in learning styles, self-expression, and communication styles (Bennett, 1999). They can also have varied conventions and expectations for academic writing even in the same genres (Ballard \& Clanchy, 1997; Bloch \& Chi, 1995). These variables and lack of familiarity with the specialized culture and academic conventions of North America constitute a major obstacle for ESL students' success in academic writing (Chang \& Swales, 1999; Mauranen, 1993). Language itself, strategy use, and cultural and educational backgrounds are interrelated factors that all seem to affect the writing performance of ESL students.

\section{ESL Students' Strategies in Academic Writing}

The strategies employed by ESL students are both numerous and diverse. ESL students bring some L1 writing strategies with them to cope with their L2 assignments; also, they are able to alter their strategies and develop new ones to achieve the desired results (Leki, 1995). Furthermore, skilled versus unskilled writers differ in their choice and application of strategies. Skilled ESL writers are found not only to use a greater variety of strategies (Green \& Oxford, 1995), but also to use strategies more often than unskilled ESL writers $(\mathrm{He}, 2005)$. They are aware of the strategies they use and why they use them (Sommers, 1980; Zamel, 1983). Unskilled ESL writers are also able to identify their own strategies, but they have a limited notion of what composing involves and focus on local concerns in their texts (Bitchener \& Basturkmen, 2006; Raimes, 1985). Such strategies as they do use may not "lead to successful task completion" (O'Malley \& Chamot, 1990, p. 140).

\section{Chinese Graduate Students and English Education in China}

Chinese ESL students differ from ESL students from other countries in many aspects. For example, the conceptual and grammatical constructions of English and Chinese vary drastically, from phonology, morphology, to syntax and beyond (Lay, 1991; Wong, 1988). Also, Chinese ESL learners' cultural thinking and discourse organizational patterns affect their ability to write clearly in English (Gonzalez, Chen, \& Sanchez, 2001). 
English is a compulsory subject in China from grade 3 to postgraduate programs (Law, 2006). The study of English is regarded as virtually essential for acquiring technological expertise and for fostering international exchanges (Adamson \& Morris, 1997). In Chinese institutions, grammar-translation remains one of the traditional and dominant methods of English language teaching (Wang, 2007). Recent textbooks are more innovative, learnercentered, and communicatively oriented because of their incorporation of new conceptions of education and international developments in language education (Adamson \& Morris). However, the quality of the teaching and learning of English is hampered by teachers' inadequate professional training in the subject itself and in pedagogy ( $\mathrm{Wu}, 2001)$. Many teachers fail to understand the underlying principles of newer textbooks and use them in traditional ways (Jin \& Cortazzi, 2002). Many students believe that teachers, published books, and articles are the best authority. They work closely with textbooks, rely mainly on rote memorization, and appear reluctant to comment on or to analyze scholarly texts critically (Matalene, 1985; Pennycook, 1996). These cultural and educational factors may influence their thinking patterns. In addition, there is an impression that language skills are hierarchically sequenced, with writing viewed as the last skill to be practiced and mastered (Chen \& Zhang, 1998).

These insights from the literature suggest that Chinese students have difficulties in English academic writing and that they may differ in some aspects from ESL students from other countries. Many Chinese ESL graduate students have little or no experience with writing an LR in English before arriving at a Canadian university. However, little attention has been given to this group of students' experiences with writing an LR. This study was an attempt to fill this gap. Three research questions were explored in this study:

1. What are Chinese ESL graduate students' perceptions of requirements for writing an LR?

2. What are Chinese ESL graduate students' challenges in meeting the requirements for writing an LR?

3. What strategies do Chinese ESL graduate students use in the process of composing an LR?

\section{Theoretical Framework}

Many theories and models have been developed to address the various facets of ESL writing (Bereiter \& Scardamilia, 1987; Kaplan, 1966, 1987; Mohan \& Lo, 1985). Among these theories, contrastive rhetoric has played an important role in ESL writing research. Initiated in 1966 by Kaplan, contrastive rhetoric maintains that each language and culture has rhetorical conventions unique to itself. Furthermore, the linguistic and rhetorical conventions of the L1 influence a student's L2 writing. This theory was heavily criticized for its potentially reductionist, deterministic, prescriptive, and essentialist orienta- 
tion (Leki, 1997), and later Kaplan (1987) offered a weaker version. He suggested that "all of the various rhetorical modes ... are possible in any language.... The issue is that each language has certain clear preferences, so that while all forms are possible, all forms do not occur with equal frequency or in parallel distribution" (p. 10). The cross-cultural insights generated by contrastive rhetoric studies allow researchers and educators to learn and address ESL writers' special characteristics and needs. However, there are two important limitations to Kaplan's hypotheses: (a) oversimplification and overgeneralization of the differences and difficulties of ESL writing, and (b) focusing too much on transfer factors and failing to consider ESL writers' differences and problems from a developmental perspective.

Thus Mohan and Lo (1985) proposed that a general model of L2 writing should include both developmental and transfer factors. According to Mohan and Lo, sentence-level skills such as grammar, syntax, and vocabulary belong among developmental factors and are established early; ability in rhetorical organization develops late and can be influenced by students' previous educational experiences (e.g., L2 teaching practices, L1 and L2 writing practices, and academic proficiency).

With regard to transfer factors, Mohan and Lo (1985) suggest that there are both positive and negative transfers in L2 academic writing. They explain that positive transfer occurs due to the existence of universal thinking patterns present in writing conventions, which are present beyond the surface level of syntax and grammar structures. Universal thinking patterns can be considered a form of underlying structures of academic knowledge such as common components of cognitive/academic proficiency. Negative transfer occurs as a result of interference from the culture-specific rhetorical organization of the writer's L1.

In addition to negative transfer explanations, Mohan and Lo (1985) propose a number of other possible explanations for errors in ESL students' writing products such as: (a) inadequate knowledge and English skills for expressing complex ideas, (b) unfamiliarity with the cultural components of a topic, (c) greater emphasis on grammatical aspects than on organizational form, and (d) unfamiliarity with writing conventions.

Mohan and Lo's (1985) model was developed more than two decades ago. It takes into account the basic mode of English composition teaching in China, but although many investigations have been conducted since then, few have introduced a specific model for L2 genre writing. The findings of recent studies have brought more credibility to Mohan and Lo's model, which provides a comprehensive perspective for understanding our participants' experiences with writing an LR. 


\section{Methodology}

\section{Context}

This study was conducted at a medium-sized university in Canada, which attracts students from every Canadian province and more than 100 countries. English is the language of instruction and communication. International graduate students accounted for around $14 \%$ of the total number of full-time graduate/professional students registered at the university during 2005/2006. Many of them were ESL speakers. The university offers regular assistance to students who need language and writing support through free one-to-one tutorials provided by the International Centre and workshops and academic writing courses offered by the School of English and the Writing Centre.

\section{Research Participants}

In order to select information-rich participants for this study, we established the following criteria: participants were required to be Chinese-speaking graduate students who had experiences with writing an LR in English. In attempting to represent diverse disciplines and to ensure some variety in the students' experiences (Leki, 1995), three participants from science and engineering were involved in this study, as well as a student from finance: $\mathrm{Yi}$, a male master's student majoring in electrical engineering; Xiu, a female master's student studying in mechanical engineering; Will, a male master's student majoring in chemical engineering; and David, a male doctoral student from finance (all pseudonyms).

All four participants had learned English as a foreign language for at least nine years before starting their graduate program at the university. By the time of this study, all of them had had experience with writing an LR in English, ranging from once to seven times and had had their first LR writing experience when they were doing their undergraduate thesis in Chinese. But none of them had any experience with either reading or writing an LR in English before studying in Canada. Only Will had taken an academic writing course offered for graduate students. He thought that the course instruction was at his comprehension level, but beyond his writing ability.

\section{Data Collection}

Based on the three research questions and the kind of information we intended to seek from the participants, a semistructured interview was used to collect the data. The semistructured interview approach has the advantage of providing reasonably structured data across participants, but with greater depth than can be obtained from other methods (Gall et al., 1996). Besides the preplanned questions, unforeseen questions also emerged from topics or ideas that arose in participants' answers. These on-the-spot questions supplemented the main questions with either planned or unplanned probes. The 
participants were given opportunities to provide freely any information about their experiences in writing an LR.

Each participant was interviewed once for approximately 40 minutes. All the interviews were conducted primarily in English. However, participants were allowed to switch between English and Chinese during the interviews to express their meanings accurately. As a result, Chinese was used on few occasions. All interviews were audiotaped and transcribed verbatim. Once transcripts of the first round interviews became available, Will and David were interviewed a second time to clarify some specific responses. Both follow-up interviews lasted 15 minutes. Fifty-seven pages of transcript data were generated from the interviews, with an average of about 14 pages for each participant.

\section{Data Analysis}

Constant comparison was used to analyze the data. The transcripts of the interviews were read and examined continually after the data collection. When the coding was complete, the data were grouped into three categories: perceptions, challenges, and strategies. Each category was then refined and divided into subcategories. Salient and recurring themes and patterns were identified and synthesized through continual reviewing and comparing each subcategory with other subcategories across cases (Ryan \& Bernard, 2000). In our analysis, we focused on or looked for developmental factors and transfer factors as proposed by Mohan and Lo (1985), and further following their theoretical framework, we considered the context of the participants' academic, linguistic, cultural, and educational background.

\section{Findings and Discussion}

Results from this study show that the four students had varying perceptions and experiences of writing an LR. They did not perceive writing an LR as a difficult task at the time of the interview. All of them thought that writing an LR in English was essentially similar to writing one in Chinese. This resonates with Mohan and Lo's (1985) notion of positive transfer. According to them, the formulation, development, and organization of ideas were the most important factors in making a good review. David, the student from finance, had more experience with writing LRs. Engineering students' experiences were relatively impoverished until they reached the stage of writing their theses. They saw the writing challenges they encountered mainly as linguistic problems and applied some strategies to deal with these challenges.

Perceptions

These students held perceptions of an LR as an introduction, a survey, a critical survey, a summary, and a vehicle for learning. These perceptions are 
strongly consistent with the literature in this area (Boote \& Beile, 2005, 2006; Maxwell, 2006; Swales \& Feak, 2000). To Yi's understanding, an LR was intended to introduce what past work had been done on an issue, to show how his own work connected and distinguished itself from that past work, and thus to provide a rationale for conducting his research:

I think I need to introduce others' work on my subject, especially introduce their achievements. Why my research is important, have better performance? So I first introduce, review the others. Second, I compare my own with others. What's the difference between your own work and others'.

Will also thought that an LR was an introduction to a research project and that it should be a critical survey of relevant research as well. To conduct an LR, he needed to compare and evaluate the strengths and weaknesses of the literature according to the guiding concept of his own research and show how it related to his work.

Both Xiu and David believed that an LR was a vehicle for learning, to find certain methodologies and theories to work with. But they differed in that Xiu perceived an LR as a summary of relevant literature: "For the literature reviews I have written, I just summarize their ideas, summarize the contents that most related to my research." On the other hand, in David's opinion, an LR was a survey of the most recent relevant research. In addition, seeing himself as a junior researcher, David did not think that he should critically evaluate the earlier work that he cited. In his view, all research varied greatly in the validity and reliability of the methods used, the results and findings, and the researcher's interpretation of those findings. To explain his unwillingness to critique others' work, he also noted a "common sense" view as elaborated below.

I read a lot of articles. They seldom say bad things about others' work. It's kind of ethic issues. You can't just criticize other people's ideas.

Another people can judge whether you're right or maybe somebody's wrong. In some topic, I can give some remark. In some topic, they're so advanced. I'm not that qualified to give such kind of remark.

We attribute David's reluctance to evaluate the literature critically to the power imbalance between authors on one hand, who hold the authority of authorship as established faculty members, and students on the other hand. Others have suggested that this reluctance may be influenced by the concept of social harmony and the tradition of respect for the ideas of superiors in Chinese culture (Taylor \& Chen, 1991).

In addition, as discussed below, three of the four participants noted that they learned how to write an LR in English mainly through reading and modeling. This finding suggests that these students' instructors or super- 
visors might not have clarified their own perceptions of an LR before the students' actual writing although they had guided their research and observed their writing progress all along. These students' perceptions could also have been affected by their reading for content knowledge, by disciplinary traditions and conventions, and by their previous experiences with LR writing in China. These perceptions may be appropriate for particular stages of their work in their respective disciplines; moreover, it may not be appropriate to use criteria from one discipline to judge the perceptions held by students in other disciplines. To verify whether each student in this study held an adequate perception of an LR for his or her specific situation, more research needs to be done in their areas of specialization.

\section{Challenges}

Limited vocabulary. Three of the four participants observed that it was not easy for them to use appropriate vocabulary to express their ideas clearly. The exception was Will, from chemical engineering, whose supervisor advised him "to use simple and common words." David said he had no problem with terminology, but he found that it sometimes took time for him to choose an appropriate verb that specifically suited his purpose. Both Yi and

Xiu found it was difficult for them to use a variety of vocabulary to express the same ideas or convey similar concepts in one context. As Yi said,

Last sentence, I used this word. Maybe for the native speaker, the next sentence they used another word, but the same meaning. But for me, it is difficult to find the equivalent. But it feels very worse if you use the same word so many times.

Xiu said that sometimes she would look up a certain English word in the dictionary to find its usage, but she did not need to use a dictionary when she was writing in Chinese "because in mother language, you don't think hard, you can have this word."

These students' vocabulary problems may have stemmed from the fact that they did not have efficient and effective strategies for enlarging and improving their English vocabulary. Besides checking dictionaries for the meaning and usage of a certain word, the participants did not mention using any other sources to locate the vocabulary they intended to use or report having any strategies to improve their vocabulary scope. As Xiu said, "You just think, think, and think."

Earlier studies indicate that individual learner differences (e.g., background factors) are a crucial aspect in learning vocabulary, as good learners vary enormously in their choice of strategies and tend to use a wide variety of strategies in combination (Gu \& Johnson, 1996). For some Chinese students, vocabulary acquisition largely means rote memorization-list learning $(\mathrm{Gu}, 2002)$ - but vocabulary lists do not provide the necessary 
grammatical information or the context that these learners might need for their own writing. These students should be reminded that a person's knowledge of a vocabulary item "requires more than just familiarity with its meaning and form" (Schmitt \& McCarthy, 1997, p. 4). A more active approach (e.g., contextual strategies) could help them improve their vocabulary.

Sentence-level difficulties. The three participants from engineering identified sentence-level problems as one of the main difficulties in their writing of LRs. Only David, the student from finance, said he did not worry about sentence-level accuracy. He would just "follow the accepted conventions of mathematical discourse, and write in present tense." Xiu thought she had difficulty with sentence structure. Sometimes she felt she had made herself clear, but her supervisor "just could not understand." Both Yi and Will mentioned that sometimes they had to write several sentences to present one point when one more effective sentence could have done the job. In Yi's words,

I can express myself clearly, but I found the native speakers can express ideas more skillfully, in more details and more specifically. Same idea, I found I wrote a lot of sentences to make it clear. Maybe it's not clear enough for them. That's the writing skill. Maybe sometimes I feel my language is clear enough, but after I read others, I find "no, no."

Will's supervisor advised him to use simple words and sentence structures because it was easy for him to make grammatical mistakes when he tried to write long, complex sentences.

These students' emphasis on sentence-level correctness in usage and sentence variety reflects one key belief: making grammatically correct sentences is an important factor in determining if their writing is good. The formation of this belief can be traced back to their experiences of learning English as a foreign language in China. Grammar-focused teaching and learning activities can lead students to pay particular attention to specific details at the sentence level (Wang, 2007).

Paraphrasing. Paraphrasing is an important writing skill required in completing most academic writing assignments in many disciplines (Braine, 1995; Zhu, 2004). Xiu and Yi both had the feeling that they had difficulties in paraphrasing a section from a source. They often found that the original text was "already very good" and that the author's "expression is better than what I want to say." Xiu's concern was:

I can understand it, but I think their expression is better than what I want to say. Not just the vocabulary, anything, English sentence structure. I couldn't write in other sentence. I always follow their sentence. 
Yi also thought that he lacked the competence to paraphrase efficiently:

I found, normally, I can't use the same sentence as the original paper, but I have to write, change something, but use the same idea in that paper. So, I found some difficulties, because they're already very good.

It appears that both knew that the goal of paraphrasing is to preserve the sense of the original text, but not the form. Their basic concept of paraphrasing was close to the definition in the literature (Rosen \& Behrens, 1997). Accurate and efficient paraphrasing requires skill in reading, comprehension, analysis, selection of new structures and vocabulary, and integration of the source information (Barks \& Watts, 2001). The confidence that Xiu and Yi expressed in their reading ability and professional knowledge did not support the assumption that they had difficulties in understanding the original text. As they themselves indicated, their limited vocabulary and their difficulty with sentence structures affected their ability to generate an adequate paraphrase. Again, this feeling of incompetence in paraphrasing may be traced back to their cultural background: their belief that published books and articles were superior and authoritative.

\section{Strategies}

Reading and modeling. All the participants in this study believed that the best way to learn how to write an LR was to read reviews conducted by other researchers. In Will's words, "Just read relevant thesis, the relevant paper, the relevant book about the background knowledge in literature review." To meet the sentence-level challenge, one of the strategies they used was to examine the sentence structures and patterns produced by native Englishspeaking writers in professional texts. They then imitated these sentences as models to pattern their own sentences after them. As Yi noted,

I read a lot of papers, and I found how they write it. I use their sentence structure to produce, to write my own ideas. I found my sentences looked similar as theirs. That's not copy. I read a lot, so some ideas are in my mind. It's a kind of naturally reflected in my mind.

This conscious imitation of models and employment of structures collected from examples of professional writing could surely help the students to assimilate relevant genre conventions and subject knowledge (Shaw, 1991), thus improving their overall writing quality in a specific field. However, it is also necessary for the students to become aware of their own style. As Will mentioned during the interview, sometimes his supervisor would ask him to rewrite some complicated sentences he had "copied" because the particular structures were not consistent with the simple style he used in the rest of the text and, therefore, interfered with his "Chinese style" and "Chinese way" of thinking and writing. So when students write with 
cumulative structures, they need to examine the appropriateness of these sentences not only in terms of their internal construction, but also in relation to the overall context and effect.

Planning. All the participants in this study had developed their own ways of preparing a writing plan. Will constructed a definite writing plan before actually writing, and he would stick to the plan and did not change it in the process of writing. He believed that after planning, "the only thing left for you is: you need to modify your sentence. And maybe you need to change some of your sentences, just sentences, but not frame, the structure." Xiu, David, and Yi seemed to be more flexible about their writing plans. Xiu would make a mental plan and write according to that plan "most of the time." This does not mean that she refused to change. As she explained, "The plan is always changing because the plan is in my mind. It's very flexible because the main purpose is to explain clearly." David agreed that planning ahead for what he was going to write would "put your essay in a very concise and clear way. So basically, at the beginning I know what I want to write." He also revised his plan as needed in the process of writing: "The reason you change is because you have new information. You know your old idea is not going to succeed. You have to change it." In Yi's opinion, it was important to have good organization: "If the organization is good, is clear, even my language is not very clear, but the reader may have a clear idea what I'm saying." So he began the writing process by drawing up an organizational plan and made a list of ideas that he wanted to include:

First, I think about the structure, what I need to do. After having this plan, I went to find all the materials according to this plan. After my reading, I found more new ideas, some new things I need to introduce, so I added them into my plan.

Thus three of the four participants in this study were not totally constrained by their initial plans. They kept revising and improving them as new information and ideas came to light in the literature search and the writing process in the belief that writing was a recursive process. The varied decisions made by the participants imply that planning can serve varied purposes in varied contexts: it will not only help record preformed ideas, but will also help explain ideas clearly.

Using the L1 and translation. Xiu and Will said that sometimes they thought and composed in Chinese and then translated this into English. Xiu noted that she tried to think in English, but sometimes if she wanted to "explain the ideas clearly" or to "think more sophisticated thoughts," she had to think in Chinese and then translate the ideas or sentences into English. Will agreed that being able to use his L1 was an advantage for him because it was easier to retrieve background knowledge and process thoughts in the L1. At the same time, both explained that using their L1 and translation was also 
a disadvantage for them because they believed that if they were to write in English, they should think in English. As Xiu said, "If you write in English, you should think in English. This is good. And you couldn't use English to express yourself, that's bad. It's bad because you have another task, to translate it." In Xiu's view, translation was an extra stage in the composing process relative to writing directly in English. And in the translation process, as Will experienced, the resulting surface structures of many of his translations were identical or similar to the usual or normative sentence structures of his L1. He thought his writing might seem awkward to native speakers:

I think in Chinese sentence and I translate into English. Sometimes you use the sentence, maybe the Canadian, they are not familiar. You present it in Chinese way and they present it in English way. Sometimes the supervisor will ask you what's the meaning of this sentence, ask you to explain and they will change your sentence, and said you should use this way.

There are definite benefits to thinking and writing in English. Xiu and Will's ambivalent attitude toward using the L1 reflects the proposition that the best way for learners to achieve native-like control of a target language is to think in that language rather than to think in their L1 and then translate into the target language (Cohen, 1995).

Drawing on Mohan and Lo's (1985) notion of positive transfer, these students' strategy of using their L1 did not usually interfere with their writing in the L2, but rather helped them form ideas about how to go about writing. They used their L1 in looking for content knowledge, appropriate disciplinary conventions, and structures for writing. The more they used their L1 for certain topic areas, the better the quality of their organization and ideas (Lay, 1982). At the same time, when they used their L1 or L1 knowledge to plan the review structure, paragraph, and sentence, it was natural for them to bring their L1 discoursal features into their L2 writing, with the problematic presence of L1 syntax and structures. In Mohan and Lo's (1985) words, this could be called a negative transfer. Our argument is: although ESL writers should reasonably be encouraged to work in English, it is necessary to let them know that if use of the L1 and translation can lead to improved writing quality, they do not need to force themselves to think and write entirely in English.

Communication with the supervisor. Interview data seem to show that all the participants in this study worked well with their supervisor and employed this relationship as a social strategy for their writing. They sought advice and followed it. Their supervisor would read their draft, correct it, and return their writing with suggestions. For example, Xiu's supervisor, who was a nonnative speaker of English himself, encouraged her to practice writing a review regularly on various topics. He checked on her progress and revised 
each draft that Xiu turned in. He also told her what should be emphasized in a review: "Don't include everything. The conclusion is important." David believed that professors were one of the finest information resources he could count on, "the best information, best methodology, quite helpful." $\mathrm{He}$ communicated a great deal with his supervisor. His supervisor could offer the professional advice he needed at various stages of writing. In his words, "We always face with time constraints, so why not just borrow other people's idea?" These students' positive relationship with their supervisors indicates that they found supervisors/instructors to be the major and the most favorable source of advice and feedback on the writing process.

This study also shows that two of the four students conducted their LRs in relative isolation. This means that they did not or could not seek advice from people other than their supervisor (or course instructor). Will's supervisor suggested that Will ask a student colleague to proofread his writing, but Will did not follow his advice. Yi was the only master's student in his lab. His two doctoral colleagues worked at home most of the time. Only David discussed his writing with his Canadian colleagues and reported that they proofread each other's work to check for language errors and spot gaps in logic that each might not see on their own. Xiu did her experiments at a research center. Sometimes she discussed her ideas with a co-worker of her supervisor, who was her second important source for information and comments.

The relative lack of communication and cooperation with other staff and students not only limited these students' opportunities to hear other ideas and points of view, but also reduced their chances of contributing to the knowledge of others. This isolation could be due to reluctance to seek help from colleagues. The communication barriers between native-speaking and ESL students in Canadian universities are underresearched. However, our personal observation of the isolation of ESL students shows the urgency of investigation in this area.

Because these students concentrated on narrow specialty areas under the guidance of their supervisors, specialization could be another reason to explain the lack of consultation. The problem with specialization is that students may not understand problems outside their area of expertise and may completely depend on the supervisor's knowledge and judgment. However, it is unlikely that one specialist can provide all the information a student needs. In addition to the supervisor, students can also benefit from feedback from fellow members of the same discourse community. Xiu's experience at the research center suggests that other staff can also provide useful information when approached. Sometimes student colleagues who are not in the writer's area of concentration may also be excellent sources of constructive criticism. 


\section{Conclusion}

Mohan and Lo (1985) suggested that a general model of L2 composition should include both developmental and transfer factors. Results from this interview study on LR writing provide some evidence to support this model. All four participants in this study believed that writing an LR in English was basically similar to writing one in Chinese, which indicates that these students' knowledge and previous educational experiences with writing an LR in Chinese influenced their writing an LR in English, often a positive rather than negative transfer. This transfer was important because none of the participants had any explicit instruction on how to write an LR in English. Their experiences and the academic proficiency they acquired in Canada played an important role in helping them form hypotheses about how to go about writing and may explain their lack of concern at the discourse level.

On the other hand, all of them saw the writing challenges they encountered mainly as linguistic problems at the sentence level, although they also knew that linguistic problems played a less important role in how their writing was evaluated. This result indicates that linguistic problems persist for Chinese ESL students even at an advanced level. It might have stemmed from: (a) insufficient exposure to English and lack of native-like intuitions about language, which relate to developmental factors (e.g., varied lengths of stay in Canada); or (b) continued negative transfer effects from the rhetoric of Chinese. Students in this study attributed these challenges to their Englishlanguage deficiencies.

Our analysis indicates that these students employed various strategies to deal with the kinds of challenges they encountered in the process of adapting to discipline- and genre-specific requirements. However, these strategies were far from entirely sufficient and efficient. They reflected the students' individual backgrounds and needs, as well as their broader cultural and educational backgrounds. Although these students may become more competent as they proceed through their course work, research, and thesis writing, explicit instruction in strategies could be more helpful to these students because some may not discover all that they need to learn by themselves.

This research also reveals that one-to-one, hands-on help by the supervisor may be taken as the most effective assistance for students who are writing an LR. These students' reliance on communication with their supervisors shows the crucial role of one-to-one assistance for them, but none of the participants in this study had used the university's tutorial service or attended workshops on academic writing that were available on their campus. Although there is much talk about teaching toward the individual needs of students, often ESL students may feel that they are treated as a homo- 
geneous group in such settings and that their differences are rarely addressed in ESL programs.

To better meet such students' needs, writing services could collaborate with departments across the campus in identifying the specific writing challenges faced by these students, and continually adjust the program based on the students' needs and progress and on their supervisors' feedback. There is not much research on the quality and effectiveness of such programs or on whether they are culturally accommodating for ESL students without implicitly casting them as "less able" students (Benesch, 1993). Equally important is to give these students time for exposure to the L2 through reading well-written literature and practicing more genre-specific writing for linguistic form and style.

In this study, we asked our participants if they had had any experience with either reading or writing an LR before studying in Canada. We did not investigate in depth if they had encountered any challenges while writing an LR in their L1 or what strategies they had employed to tackle these challenges. In the future, it would be worth doing a comparative study by asking the students to provide samples of LRs they had written in both the L1 and the L2. By examining the texts in both languages with the students, we might learn: (a) if they are likely to produce a wider range of syntactic structures in the L1 or evince a restricted range of syntactic structures as in the L2; (b) how, if at all, their L1 competence relates to their L2 competence; (c) if the strategies they use in L1 writing are similar to those they use in L2 writing; and (d) how the writing strategies used in each of the two languages differ.

At the least, this study shows that more research is needed on students in particular language groups and their experiences in learning to conduct LRs in genre-specific contexts. Mohan and Lo's (1985) framework has been shown to be a useful approach in this quest.

\section{Acknowledgments}

We thank Dr. Howard Smith and Dr. Marie Myers for their constructive feedback and insightful comments on an earlier version of this article.

\section{The Authors}

Jun Qian is a doctoral student in the Faculty of Education, Queen's University. Her main research interests are in intercultural communication issues, second-language writing, and internationalization of curriculum. She has published in CBIE Research.

Eva Krugly-Smolska is an associate professor in the Faculty of Education, Queen's University. Her expertise is in the area of multicultural education and cross-cultural science education. She is a former President of the Comparative and International Education Society of Canada and former Editor of its journal. 


\section{References}

Adamson, B., \& Morris, P. (1997). Focus on curriculum change in China and Hong Kong: The English curriculum in the People's Republic of China. Comparative Education Review, 41(1), 3-26.

Angelova, M., \& Riazantseva, A. (1999). “If you don't tell me, how can I know?": A case study of four international students learning to write the U.S. way. Written Communication, 16(4), 491-525.

Ballard, B., \& Clanchy, J. (1997). Teaching international students: A brief guide for lecturers and supervisors. Deakin, ACT: Education Australia.

Barks, D., \& Watts, P. (2001). Textual borrowing strategies for graduate-level ESL writers. In D. Belcher \& A. Hirvela (Eds.), Linking literacies: Perspectives on L2 reading-writing connections (pp. 246-267). Ann Arbor, MI: University of Michigan Press.

Benesch, S. (1993). ESL, ideology, and the politics of pragmatism. TESOL Quarterly, 27, 705-717.

Bennett, C.I. (1999). Comprehensive multicultural education: Theory and practice (4th ed.). Boston, MA: Allyn \& Bacon.

Bereiter, C., \& Scardamilia, M. (1987). The psychology of written composition. Hillsdale, NJ: Erlbaum.

Bitchener, J., \& Basturkmen, H. (2006). Perceptions of the difficulties of postgraduate L2 thesis students writing the discussion section. Journal of English for Academic Purposes, 5, 4-18.

Bloch, J., \& Chi, L. (1995). A comparison of the use of citations in Chinese and English academic discourse. In D. Belcher \& G. Braine (Eds.), Academic writing in a second language: Essays on research and Pedagogy (pp. 231-274). Norwood, NJ: Ablex.

Boote, D.N., \& Beile, P. (2005). Scholars before researchers: On the centrality of the dissertation literature review in research preparation. Educational Researcher, 34(6), 3-15.

Boote, D.N., \& Beile, P. (2006). On "Literature reviews of, and for, educational research": A response to the critique by Joseph Maxwell. Educational Researcher, 35(9), 32-35.

Braine, G. (1995). Writing in the natural sciences and engineering. In D. Belcher \& G. Braine (Eds.), Academic writing in a second language: Essays on research and pedagogy (pp. 113-134). Norwood, NJ: Ablex.

Brown, J.D. (1988). Understanding research in second language learning: A teachers guide to statistics and research design. Cambridge, UK: Cambridge University Press.

Bruce, C.S. (1994). Research students' early experiences of the dissertation literature review. Studies in Higher Education, 19, 217-229.

Casanave, C.P. (2002). Writing games: Multicultural case studies of academic literacy practices in higher education. Mahwah, NJ: Erlbaum.

Casanave, C.P., \& Hubbard, P. (1992). The writing assignments and writing problems of doctoral students: Faculty perceptions, pedagogical issues, and needed research. English for Specific Purposes, 11(1), 33-49.

Chang, Y., \& Swales, J.M. (1999). Informal elements in English academic writing: Threats or opportunities for advanced non-native speakers? In C.N. Candlin \& K. Hyland (Eds.), Writing: Texts, processes, and practices (pp. 145-167). London: Longman.

Chen, C., \& Zhang, Y. (1998). A perspective on the college English teaching syllabus in China. TESL Canada Journal, 15(2), 69-74.

Cohen, A.D. (1995). In which language do/should multilinguals think? Language, Culture and Curriculum, 8(2), 99-113.

Connor, U.M., \& Kramer, M.G. (1995). Writing from sources: Case studies of graduate students in business management. In D. Belcher \& G. Braine (Eds.), Academic writing in a second language: Essays on research and pedagogy (pp. 155-182). Norwood, NJ: Ablex.

Cooley, L., \& Lewkowicz, J. (1997). Developing awareness of the rhetorical and linguistic conventions of writing a thesis in English: Addressing the needs of EFL/ESL postgraduate 
students. In A. Duszak (Ed.), Culture and styles of academic discourse (pp. 113-129). New York: Mouton de Gruyter.

Dong, Y.R. (1996). Learning how to use citations for knowledge transformation: Non-native doctoral students' dissertation writing in science. Research in the Teaching of English, 30, 428-457.

Gall, M.D., Borg, W.R., \& Gall, J.P. (1996). Educational research: An introduction (6th ed.). White Plains, NY: Longman.

Gonzalez, V., Chen, C., \& Sanchez, C. (2001). Cultural thinking and discourse organizational patterns influencing writing skills in a Chinese English-as-a-foreign language (EFL) learner. Bilingual Research Journal, 25, 417-442.

Green, J.M., \& Oxford, R. (1995). A closer look at learning strategies, L2 proficiency, and gender. TESOL Quarterly, 29, 261-297.

$\mathrm{Gu}, \mathrm{Y}$. (2002). Gender, academic major, and vocabulary learning strategies of Chinese EFL learners. RELC Journal, 33(1), 35-54.

$\mathrm{Gu}$, Y., \& Johnson, R.K. (1996). Vocabulary learning strategies and language learning outcomes. Language Learning, 46, 643-679.

He, T. (2005). Effects of mastery and performance goals on the composition strategy use of adult EFL writers. Canadian Modern Language Review, 61, 407-431.

Hyland, K. (1999). Academic attribution: Citation and the construction of disciplinary knowledge. Applied Linguistics, 20(3), 341-367.

Jin, L., \& Cortazzi, M. (2002). English language teaching in China: A bridge to the future. Asia-Pacific Journal of Education, 22(2), 53-64.

Kaplan, R.B. (1966). Cultural thought patterns in inter-cultural education. Language Learning $16,1-20$.

Kaplan, R.B. (1987). Cultural thought patterns revisited. In U. Connor \& R.B. Kaplan (Eds.), Writing across languages: Analysis of L2 text (pp. 9-21). Reading, MA: Addison-Wesley.

Kwan, B.S.C. (2006). The schematic structure of literature reviews in doctoral theses of applied linguistics. English for Specific Purposes, 25, 30-55.

Law, W. (2006). Education reform for national competitiveness in a global age: The experience and struggle of China. In K. Mazurek \& M.A. Winzer (Eds.), Schooling around the world: Debates, challenges, and practices (pp. 68-103). Toronto, ON: Pearson Education.

Lay, N.D.S. (1982). Composing processes of adult ESL learners: A case study. TESOL Quarterly, $16,406$.

Lay, N.D.S. (1991). A contrastive guide to teach English to Chinese students. (ERIC Document Reproduction Service No. ED363119)

Leki, I. (1995). Coping strategies of ESL students in writing tasks across the curriculum. TESOL Quarterly, 29, 235-260.

Leki, I. (1997). Cross-talk: ESL issues and contrastive rhetoric. In C. Severino, J.C. Guerra \& J.E. Butler (Eds.), Writing in multicultural settings (pp. 234-244). New York: Modern Language Association of America.

Leki, I., \& Carson, J.G. (1994). Students' perceptions of EAP writing instruction and writing needs across the disciplines. TESOL Quarterly 28, 81-101.

Matalene, C. (1985). Contrastive rhetoric: An American writing teacher in China. College English, 47, 789-808.

Mauranen, A. (1993). Cultural differences in academic rhetoric: A text linguistic study. Frankfurt am Main: Peter Lang.

Maxwell, J.A. (2006). Literature reviews of, and for, educational research: A commentary on Boote and Beile's "Scholars Before Researchers." Educational Researcher, 35(9), 28-31.

Meloy, J.M. (2002). Writing the qualitative dissertation: Understanding by doing (2nd ed.). Mahwah, NJ: Erlbaum.

Miguel, C.S., \& Nelson, C.D. (2007). Key writing challenges of practice-based doctorates. Journal of English for Academic Purposes, 6(1), 71-86. 
Mohan, B.A., \& Lo, A.W. (1985). Academic writing and Chinese students: Transfer and developmental factors. TESOL Quarterly, 19, 515-534.

O'Malley, J.M., \& Chamot, A.U. (1990). Learning strategies in second language acquisition. Cambridge, UK: Cambridge University Press.

Paltridge, B. (1997). Thesis and dissertation writing: Preparing ESL students for research. English for Specific Purposes, 16, 61-70.

Pennycook, A. (1996). Borrowing others' words: Text, ownership, memory, and plagiarism. TESOL Quarterly, 30, 201-230.

Prior, P.A. (1998). Writing/disciplinarity: A sociohistoric account of literate activity in the academy. Mahwah, NJ: Erlbaum.

Railey, P. (1997). Literature reviews: Obtaining perspective. (ERIC Document Reproduction Service No. ED415695)

Raimes, A. (1985). What unskilled ESL students do as they write: A classroom study of composing. TESOL Quarterly, 19, 229-258.

Rosen, L.J., \& Behrens, L. (1997). The Allyn \& Bacon handbook (3rd ed.). Boston, MA: Allyn \& Bacon.

Ryan, G.W., \& Bernard, H.R. (2000). Data management and analysis methods. In N.K. Denzin \& Y.S. Lincoln (Eds.), Handbook of qualitative research (2nd ed., pp. 769-802). Thousand Oaks, CA: Sage.

Schmitt, N., \& McCarthy, M. (Eds.). (1997). Vocabulary: Description, acquisition and pedagogy. Cambridge, UK: Cambridge University Press.

Shaw, P. (1991). Science research students' composing processes. English for Specific Purposes, 10, 189-206.

Silva, T. (1993). Toward an understanding of the distinct nature of L2 writing: The ESL research and its implications. TESOL Quarterly, 27, 657-677.

Sommers, N. (1980). Revision strategies of student writers and experienced adult writers. College Composition and Communication, 31, 378-388.

Swales, J.M., \& Feak, C.B. (2000). English in today's research: A writing guide. Ann Arbor, MI: University of Michigan Press.

Taylor, G., \& Chen, T. (1991). Linguistic, cultural, and subcultural issues in contrastive discourse analysis: Anglo-American and Chinese scientific texts. Applied Linguistics, 12, 319-336.

Thompson, P. (2005). Points of focus and position: Intertextual reference in PhD theses. Journal of English for Academic Purposes, 4, 307-323.

Wang, A. (2007). Teaching aviation English in the Chinese context: Developing ESP theory in a non-English speaking country. English for Specific Purposes, 26, 121-128.

Wong, S.C. (1988). What we do and don't know about Chinese learners of English: A critical review of selected research. RELC Journal, 19(1), 1-20.

$\mathrm{Wu}, \mathrm{Y}$. (2001). English language teaching in China: Trends and challenges. TESOL Quarterly, 35, 191-194.

Zamel, V. (1983). The composing processes of advanced ESL students: Six case studies. TESOL Quarterly, 17, 165-187.

Zhu, W. (2004). Writing in business courses: An analysis of assignment types, their characteristics, and required skills. English for Specific Purposes, 23, 111-135. 